\title{
Cognitive profile in middle-aged and older bipolar patients
}

\author{
Cristiana Elce ${ }^{1 *}$, Mariangela Falco ${ }^{1}$, Sarah Ammendola ${ }^{1}$, Stefano Orlando ${ }^{1}$, Diana Galletta ${ }^{1}$, Nina Fragassi ${ }^{2}$, \\ Margherita Casiello ${ }^{1}$ \\ From $1^{\text {st }}$ International Congress on Neurobiology and Clinical Psychopharmacology and European \\ Psychiatric Association Conference on Treatment Guidance \\ Thessaloniki, Greece. 19-22 November 2009
}

\section{Background}

Cognitive deficits are reported in euthymic and acute phases of bipolar disorder(BD) [1]. However, only few studies have previously evaluated the cognitive profile of middle-aged and older patients affected by BD $[2,3]$. The main purpose of our study was to analyze the cognitive profile of bipolar patients aged between 45 and 70 years.

\section{Materials and methods}

36 patients with BD (DSM IV-TR) (25 with BD-I and 11 with BD-II) who complained a recent onset of cognitive deficits, were recruited from 2004 to 2009 at the Psychiatric Day-Hospital service of the University Medical School "Federico II". All patients underwent a comprehensive Neuropsychological assessment, focusing on short- and long-term mnesic and executive functions.

A control group was composed by 37 outpatients (45-70 years), followed by the Neuropsychological service for recent outbreaks of cognitive disorders. Exclusion criteria for the control group were psychiatric or neurodegenerative disease as well as cranial trauma.

\section{Results}

No statistically significant differences were found between the study population and the control group with respect to the neuro-cognitive profile, even though patients affected by BD-I showed poorer performance in the executive functions, in the oral span and in the logical abstractive skills, when compared to the ones affected by BD-II and to the control-group patients.

\section{Conclusions}

Greater focus should be put on cognitive aspects of BD: in particular, in our sample, patients affected by BD-I seem to have a more severe cognitive profile compared with BD-II patients. Further investigations, hopefully with larger samples, are desirable to confirm these findings.

\section{Author details}

'Department of Neuroscience Section of Psychiatry, University Medical School Federico II, Naples, Italy. ${ }^{2}$ Department of Neurology Section of Neuropsychology, University Medical School Federico II, Naples, Italy.

\section{Published: 22 April 2010}

\section{References}

1. Goldberg JF, Burdick KE: Cognitive dysfunction in bipolar disorder, a guide for clinicians. American Psychiatric Publishing, Inc 2008.

2. Silva D, Santana I, Simoes do Couto F, Maroco J, Guerreiro M, de Mendonça A: Cognitive deficits in middle-aged and older adults with bipolar disorder and cognitive complaints: Comparison with mild cognitive impairment. Int J Geriatr Psychiatry 2009, 24:624-631.

3. Delaloye C, Moy G, Baudois S, de Bilbao F, Dubois Remund C, Hofer F, Ragno Paquier C, Campos L, Weber K, Gold G, Moussa A, Meiler CC, Giannakopoulos P: Cognitive features in euthimic bipolar patiets in old age. Bipolar Disord 2009.

doi:10.1186/1744-859X-9-S1-S174

Cite this article as: Elce et al:: Cognitive profile in middle-aged and older bipolar patients. Annals of General Psychiatry 2010 9(Suppl 1):S174. 